\title{
Краевое легирование в графеновых приборах на подложках $\mathrm{SiO}_{2}$
}

\author{
(С Г.Ю. Васильева ${ }^{1}$, Д. Смирнов ${ }^{2}$, Ю.Б. Васильев ${ }^{1}$, А.А. Грешнов ${ }^{1}$, R.J. Haug $^{2}$ \\ ${ }^{1}$ Физико-технический институт им. А.Ф. Иоффе Российской академии наук, \\ 194121 Санкт-Петербург, Россия \\ ${ }^{2}$ Institut fur Festkorperphysik, Leibniz Universitat Hannover, \\ D-30167 Hannover, Germany \\ E-mail: a_greshnov@hotmail.com
}

Поступила в Редакцию 29 апреля 2019 г. В окончательной редакции 6 мая 2019 г. Принята к публикации 6 мая 2019 г.

\begin{abstract}
Экспериментально изучена проводимость лент монослойного и двухслойного графена шириной $0.5-4$ мкм, изготовленных методом плазменного травления в кислороде. Обнаружена зависимость концентрации электронов в графене от ширины ленты. Этот эффект объясняется краевым легированием графена за счет дефектов, расположенных в $\mathrm{SiO}_{2}$ вблизи краев ленты. Предложен способ формирования резких $p-n$-переходов в графене и структур с постоянным градиентом концентрации электронов в плоскости графена с помощью краевого легирования.
\end{abstract}

Ключевые слова: графен, краевое легирование, подложка, дефекты, плазменное травление.

DOI: 10.21883/FTP.2019.12.48627.9151

\section{1. Введение}

Графен считается основным материалом для создания новой углеродной электроники благодаря его выдающим транспортным свойствам [1,2], характерным для материалов с нулевой шириной запрещенной зоны и дираковским законом дисперсии электронов и дырок. Поскольку при изготовлении многих устройств графен наносится на изолирующую подложку, для практических применений важными являются вопрос влияния подложки на транспортные свойства графена посредством внесения дополнительных носителей и рассеяния, а также изучение возможностей использования этих факторов при разработке новых приборов. Такие исследования проводились в работах $[3,4]$ в применении к образцам графена, а также в работах (см. обзор [5]) на нанолентах графена, т.е. образцах шириной 100 нм и менее, в которых принципиальную роль играют оборванные связи на краях наноленты. При этом влияние подложки на краевое легирование и рассеяние графенового образца, сформированного в форме ленты, ранее не рассматривалось.

В настоящей работе показано, что экспериментальная зависимость концентрации носителей от ширины графенового образца не может быть обусловлена исключительно оборванными связями. Нами впервые указан новый источник электронов - дефекты, расположенные в подложке $\mathrm{SiO}_{2}$ вблизи краев ленты. Обнаруженная корреляция между концентрацией электронов в графене и шириной ленты позволила разработать новую концепцию приборов на основе графена. Мы предлагаем новый метод создания резких $p-n$-переходов в графене, положением и высотой которых можно управлять с помощью напряжения на затворе. Кроме того, предложена схема устройства на основе полевого транзистора с изменяющейся концентрацией носителей вдоль плоскости устройства, что приводит к непрерывному сдвигу точки Дирака вдоль канала транзистора. Путем подстройки электрического потенциала затвора такое устройство обратимо трансформируется между режимами $n$ - и $p$-типа проводимости, а также может работать в режиме плавного $p-n$-перехода. Такой электрически подстраиваемый транзистор может быть интересен для различных применений в электронике, в частности для создания программируемых логических устройств и фотодиодов на основе графена.

\section{2. Экспериментальные методики и технология}

Образцы монослойного и двухслойного графена изготавливались микромеханическим расслоением из натурального объемного графита с помощью клейкой ленты и помещались на кремниевую пластину с сильным $p$-легированием, покрытую диоксидом кремния $\left(\mathrm{SiO}_{2}\right)$ толщиной 330 нм. Для структурирования пленок (чешуек) графена в форме холловских мостиков заданной ширины и изготовления контактов в наших экспериментах применялось плазменное травление графена в атмосфере кислорода и электронно-лучевая литография с помощью сканирующего электронного микроскопа (СЭМ). Вначале на образец наносились два слоя лака - полиметилметакрилат (РММА) в этиллактате (4\%, 200K), затем РММА в анизоле $(2 \%, 950 \mathrm{~K})$. Суммарная толщина слоев составляла всего лишь 175 нм, поэтому для равномерного распределения использовалась центрифуга, в которой образец удерживался с помощью вакуума и раскручивался до 4000 об/мин в течение 60 с. C помощью оптического микроскопа в максимальном разрешении определялась область ленточной формы 
определенных размеров, в которой и формировался окончательный образец графена, а оставшаяся площадь подвергалась облучению электронным пучком СЭМ, после чего подвергшийся облучению лак растворяли в специальном проявителе, основой которого является метилизобутилкетон. После проявления подложка с графеном нагревалась при температуре $950^{\circ} \mathrm{C}$ в течение 5 мин, затем образец помещался в плазму кислорода на 120 с при мощности $100 \mathrm{BT,} \mathrm{в} \mathrm{результате} \mathrm{после} \mathrm{плаз-}$ менного травления оставалась только область образца, закрытая лаком.

Все образцы были структурированы в форме мостиков Холла разной ширины, на тыльной стороне подложки был нанесен металлический контакт, к которому прикладывалось затворное напряжение. Контакты с графеновым слоем были изготовлены с помощью обычной электронно-лучевой литографии и электронно-лучевого испарения с последующим осаждением слоев $\mathrm{Cr}$ и $\mathrm{Au}$. Фотография одного из образцов, полученная с помощью оптического микроскопа, показана на рис. $1, b$. Для этого образца расстояние между продольными электродами и ширина образца составляли 1.8 и 1.1 мкм соответственно. При магнетотранспортных измерениях образцы были установлены в центре сверхпроводящего соленоида так, чтобы магнитное поле $\mathbf{B}$, величина которого варьировалось от 0 до 13 Тл, было ориентировано перпендикулярно плоскости графенового слоя. Измерения проводились при температурах от $T=1.5$ до $200 \mathrm{~K}$. Сопротивление образцов определялось из величины напряжения на потенциальных контактах, измеренного с помощью синхронизирующих усилителей при токах смещения от 100 до 200 нА. Концентрация носителей заряда в образцах менялась путем подачи напряжения смещения на затворе $U_{b g}$.

\section{3. Экспериментальные результаты}

На рис. 1, а показаны зависимости сопротивления образца $\rho_{x x}$ (фотография которого приведена на вставке к рис. $1, b)$, а также концентрации носителей заряда от напряжения на затворе в нулевом магнитном поле при $T=1.5 \mathrm{~K}$. Концентрация носителей определялась из положений минимумов осцилляций Шубникова-де Гааза при различных значениях напряжения на затворе, как показано на рис. $1, b$ (для двух значений затворного напряжения $U_{b g}$ ). Максимум удельного сопротивления определяется положением точки нейтральности заряда (дираковская точка) при $U_{D}=-3.4 \mathrm{~B}$, что свидетельствует о легировании $n$-типа.

Подробные исследования эффектов краевого легирования были выполнены на составных образцах (рис. 2). Геометрическая форма таких образцов получалась при использовании плазменного травления в атмосфере кислорода. Каждый образец состоит из двух частей разной ширины, называемых широкой и узкой. Длина каждой области составляет 2.4 мкм для образца монослойного
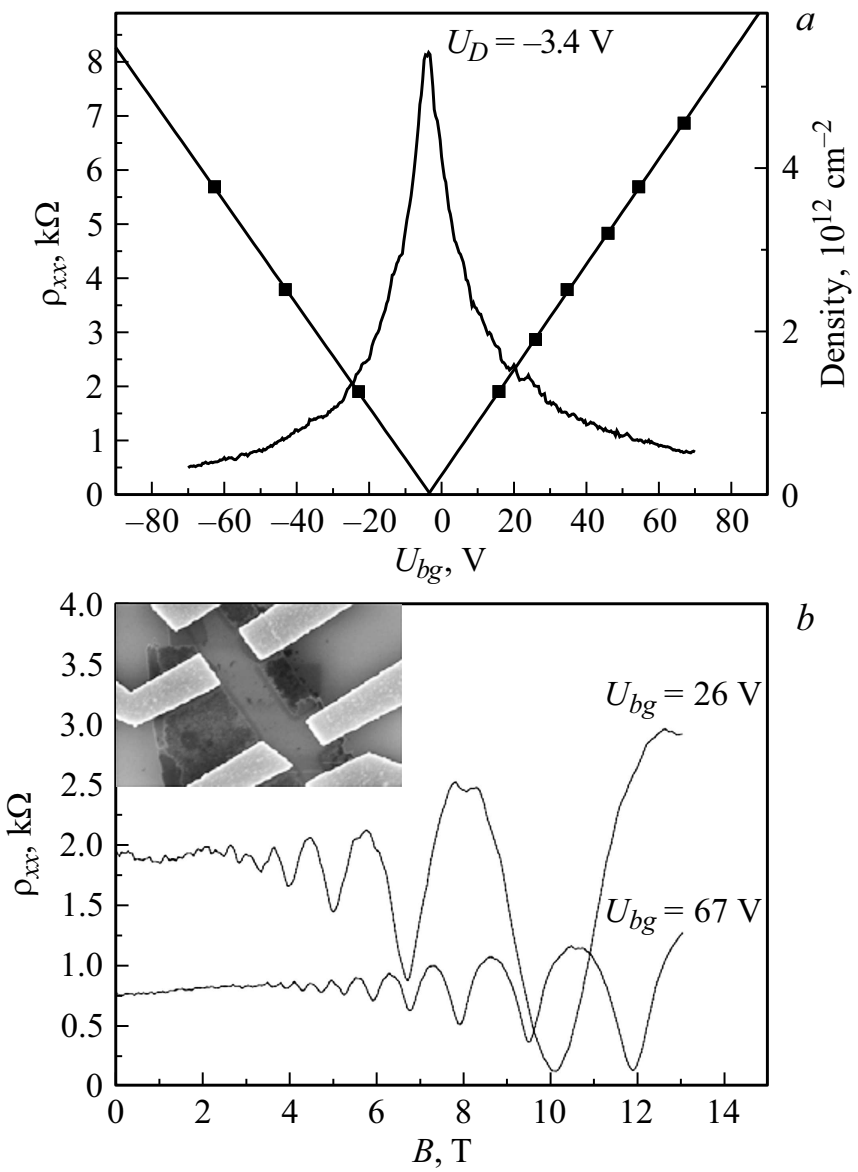

Рис. 1. $a-$ зависимости удельного сопротивления образца и концентрации носителей заряда от напряжения на затворе $U_{b g}$ в нулевом магнитном поле при $T=1.5 \mathrm{~K} . b-$ осцилляции Шубникова-де Гааза при напряжениях на затворе $U_{b g}=26$ и $67 \mathrm{~B}$; на вставке - фотография образца, полученная в оптическом микроскопе.

графена и 1.8 мкм для двухслойного графена. Для монослойного графена ширина была 2 (широкая часть) и 0.6 мкм (узкая), а для двухслойного графена 1.8 и 0.5 мкм.

На рис. 3, $a$ и $b$ показаны зависимости сопротивления от напряжения на затворе $U_{b g}$ для разных областей и образцов. Монослойный и двухслойный графен характеризуются одинаковым поведением. Узкая часть обоих образцов имеет большое сопротивление, достигающее в точке Дирака 33 кОм для монослойного образца и 45 кОм для двухслойного. Сопротивление обоих образцов в дираковской точке сильно уменьшается с увеличением ширины образцов. Важно отметить, что положение точки Дирака зависит от ширины. Это означает, что концентрация носителей заряда разная в одном и том же образце, но в разных частях с разной шириной. По напряжению на затворе в точке Дирака может быть рассчитана величина легирования, которая согласно данным на рис. 3 составила для монослойного графена $1.6 \cdot 10^{12}$ и $8.1 \cdot 10^{11} \mathrm{~cm}^{-2}$ для узкой и широкой 

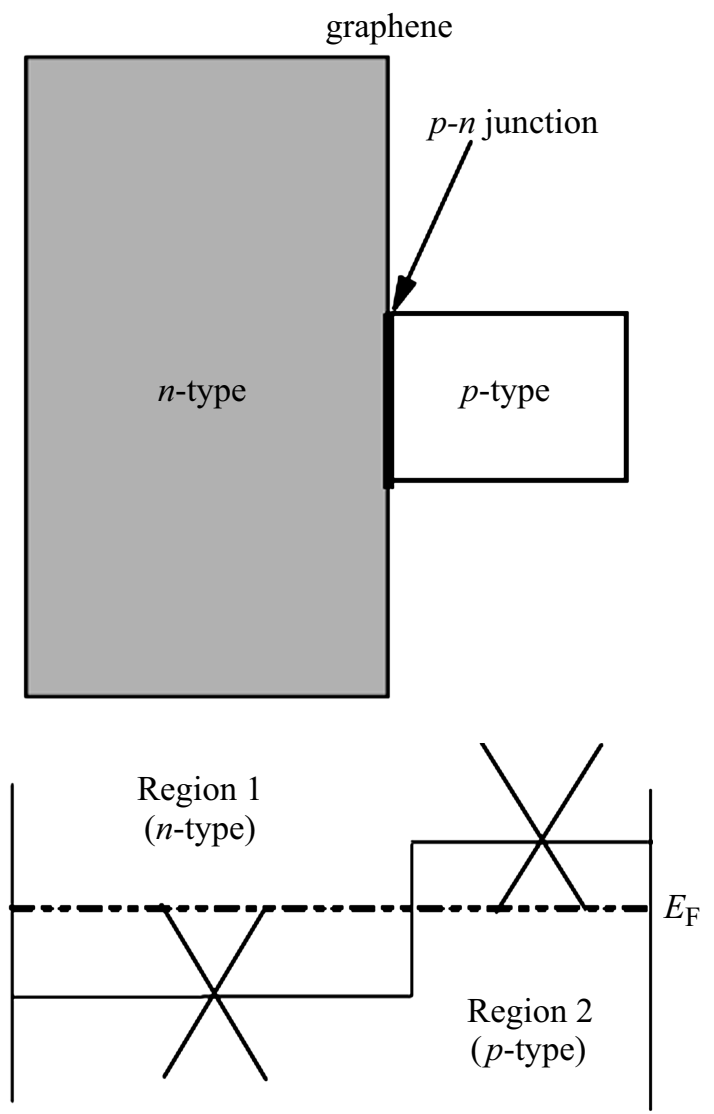

Рис. 2. Форма составного образца графена, содержащего две области с разной шириной, и условная электрическая диаграмма такого образца, показывающая формирование $p-n$-перехода при определенном значении напряжения на затворе, смещающем уровень Ферми $E_{\mathrm{F}}$ в положение между точками Дирака для разных частей образца (резкий $p-n$-переход).

частей соответственно, для двухслойного графена $7.5 \cdot 10^{11}$ и $2 \cdot 10^{10} \mathrm{~cm}^{-2}$ для узкой и широкой частей соответственно.

Эти данные явно указывают на тот факт, что край образца является источником легирования. Механизмом краевого легирования мы считаем заряженные дефекты, возникающие в $\mathrm{SiO}_{2}$ при кислородном плазменном травлении либо оказывающиеся после стравливания графена за пределами сформированной формы графенового образца, как показано на рис. 4. Заметим, экспериментально измеренная концентрация краевого легирования не может быть объяснена оборванными связями на крае образца [6], так как при этом линейная концентрация зарядов на крае приближается к атомной, что невыгодно с энергетической точки зрения. Таким образом, можно утверждать, что источником краевого легирования являются дефекты на поверхности подложки, расположенные в непосредственной близости от краев графена.

Носители с уровней электронных дефектов подложки (вне пленки графена) могут переходить в графен, как это показан на энергетической диаграмме (рис. 4). В ка- честве источников дополнительных носителей заряда в графене могут выступать как различные дефекты, закрепившиеся на свободной поверхности кварца (не покрытой графеном), образовавшиеся (или даже просто освободившиеся от покрывавшей их пленки графена) в процессе плазменного травления образца, так и молекулы, захваченные на оборванных связях на границе пленки. Мы оцениваем масштаб расстояний от края графена, на котором примеси на подложке могут эффективно легировать графен, как 100 нм (эта величина соответствует расстоянию, на котором находятся легирующие примеси в обычных полупроводниковых гетероструктурах [7]). Эта оценка может быть получена из тех соображений, что на больших расстояниях кулоновский потенциал заряженного центра, расстояние до которого определяется толщиной пленки диоксида кремния 330 нм, будет уже чувствоваться в подложке. Поэтому такие центры будут эффективно экранироваться электронами подложки и не
\#A

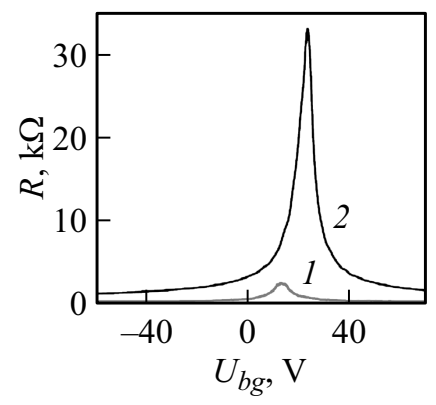

\#B

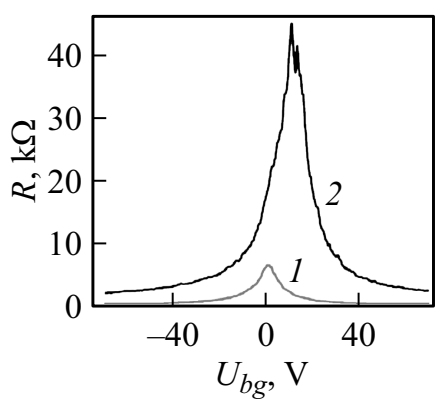

Рис. 3. Зависимости сопротивления $R$ монослойного графена (образец \#А) и двухслойного графена (образец \#В) от напряжения на затворе $U_{b g}$ в нулевом магнитном поле при $T=1.5 \mathrm{~K}$. Форма составного образца показана на рис. $2: 1-$ область 1,2 - область 2 .
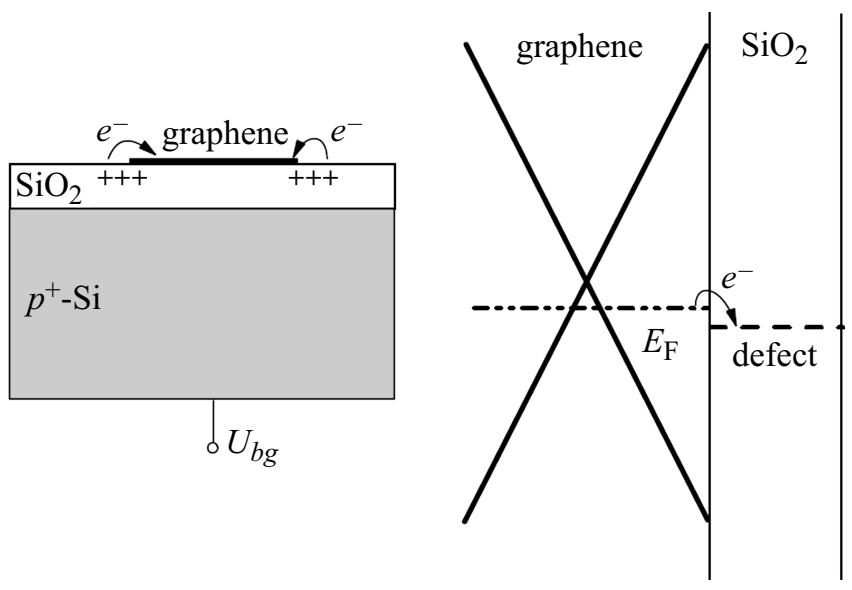

Рис. 4. Схематическое изображение переходов электронов из дефектов в подложке $\mathrm{SiO}_{2}$ в графен, иллюстрирующее механизм краевого легирования в графене, а также энергетическая зона графена и энергетическая диаграмма дефектного уровня на поверхности $\mathrm{SiO}_{2}$, соответствующая $p$-легированию. 
окажут влияния на концентрацию двумерных электронов графена. В принципе энергетические уровни электронных дефектов могут лежать как выше, так и ниже уровня Ферми в графене, соответственно дополнительное краевое легирование может быть как $n$-, так и $p$-типа.

Как следует из наших измерений, с уменьшением ширины графеновой пленки растет концентрация дырок. Это означает, что краевое легирование приводит к $p$-типу проводимости в графене, что согласуется с результатами работ $[8,9]$, где сообщалось о высокой концентрации легирования графена за счет окисления. Отмечалось, что образец с непреднамеренным окислением показал более высокое $p$-легирование (по-видимому, на краях и в местах дефектов), чем образцы без окисления.

Отметим, что наши данные согласуются с предыдущими исследованиями, выполненными преимущественно на нанолентах графена [10], которые представляют собой длинные полосы графена шириной всего в несколько десятков нанометров. В таких образцах наблюдается сильная зависимость характеристик от ширины. Как следует из наших измерений, это свойство сохраняется и для значительно более широких образцов графена, шириной несколько мкм. Мы показали, что дефекты, располагающиеся вблизи краев графена оказывают заметное влияние на свойства образцов графена шириной в несколько мкм, т.е. на 1.5-2 порядка больше, чем ширина нанолент. При этом значительная доля электронов поступает от центров, находящихся на поверхности подложки (в нашем случае это $\mathrm{SiO}_{2}$ ). Меняя ширину таких лент, можно изменять концентрацию электронов в графене. Более того, если изначально не структурированный образец графена обладал $n$-типом проводимости, уменьшение его ширины приводит к изменению типа проводимости в нем.

Обнаруженная зависимость концентрации носителей в графеновых лентах от их ширины может быть использована для создания электронных приборов. Рассмотрим метод создания $p-n$-переходов. В отличие от обычных полупроводниковых материалов, $p-n$-переход в графене обычно искусственно создают с помощью специальной конфигурации электростатических затворов, которые позволяют локально контролировать положение уровня Ферми относительно дираковской точки. В качестве альтернативы может использоваться химическое легирование, использующее перенос заряда от молекулярных адсорбентов, которое более эффективно для достижения одного типа доминирующих носителей заряда. Мы показываем новый подход к созданию резких $p-n$-переходов в графене, положением и высотой которых можно управлять с помощью напряжения на затворе. Подход основан на зависимости концентрации электронов от ширины образца графена. На рис. 2 приведена схема составного образца графена, содержащего две области с разной шириной и условная энергетическая диаграмма такого образца, показывающая формирование $p-n$-перехода при определенном напряжении на затворе, смещающем уровень Ферми в положение между точками Дирака для

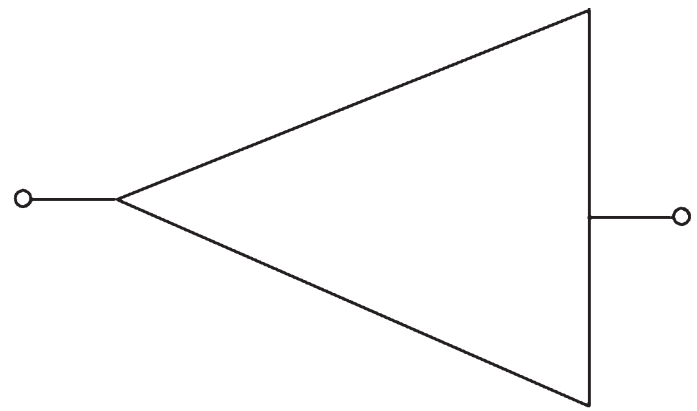

$a$

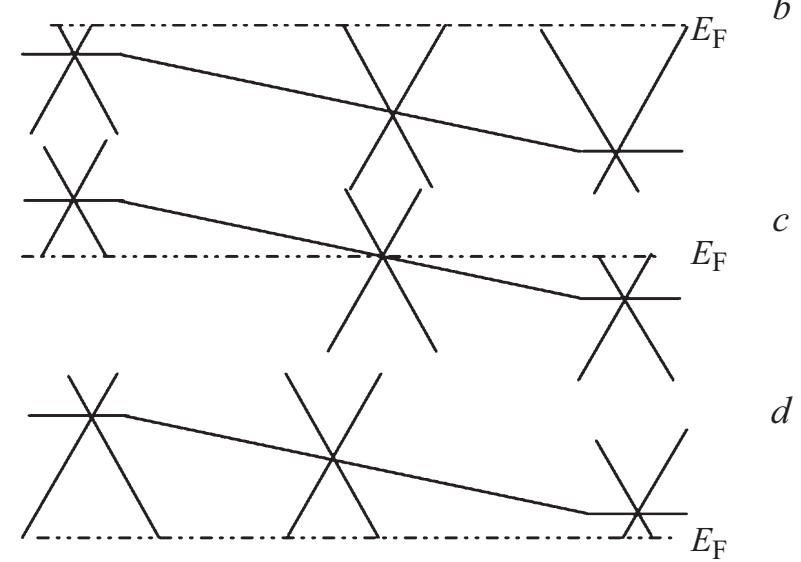

Рис. 5. $a$ - графеновая структура в форме треугольника, в которой образуется постоянный градиент концентрации носителей заряда в плоскости образца. $b-d-$ схематическая зонная диаграмма для разных типов проводимости в зависимости от положения уровня Ферми $E_{\mathrm{F}}$, подстраиваемого напряжением на затворе: $b$ - униполярный $n$-тип проводимости, $c$ - амбиполярный тип проводимости, соответствует плавному $p-n$-переходу, $d-$ униполярный $p$-тип проводимости.

разных частей образца (резкий $p-n$-переход). При этом для создания $p-n$-перехода нет необходимости изготавливать образец, в котором изначально имеются части с различным типом проводимости. Все, что требуется, это иметь две части графена с различной концентрацией носителей, поскольку, управляя напряжением на затворе, можно легко разместить уровень Ферми между точками Дирака в двух соседних областях образца с различной концентрацией носителей.

Помимо резкого $p-n$-перехода, наша концепция позволяет получить и плавный $p-n$-переход, если изготовить образцы соответствующей формы, как показано на рис. 5, $a$, где представлена схема устройства на основе полевого транзистора с изменяющейся концентрацией носителей вдоль плоскости устройства, что приводит к непрерывному сдвигу точки Дирака вдоль канала транзистора. Путем подстройки электрического потенциала затвора такое устройство обратимо трансформируется между режимами $n$ - и $p$-типа проводимости, а также может работать в режиме плавного $p-n$-перехода. Такой электрически подстраиваемый транзистор может быть интересен для различных применений в электронике, в 
частности для создания программируемых логических устройств и фотодиодов на основе графена. Варьируя положение уровня Ферми, которое зависит от напряжения на затворе, можно получить различные режимы проводимости, как показано на рис. $5, b, c, d$.

\section{4. Заключение}

Итак, мы сообщили об исследовании влияния краев на электрический транспорт в моно- и двухслойном графене. Образцы специальной формы, изготовленные методом плазменного травления, позволили установить нетривиальную зависимость электронных характеристик от ширины графенового образца. Мы показали, что электронные дефекты вблизи краев сильно влияют на транспортные характеристики, определяя концентрацию носителей заряда в лентах графена микрометровой и субмикрометровой толщины. Предложен новый метод создания резких и плавных $p-n$-переходов в графене, положением и высотой которых можно управлять с помощью напряжения на затворе.

\section{Финансирование работы}

Г.Ю. Васильева выполнила экспериментальные измерения при поддержке РНФ (грант 17-72-10134).

\section{Конфликт интересов}

Авторы заявляют, что у них нет конфликта интересов.

\section{Список литературы}

[1] K.S. Novoselov, A.K. Geim, S.V. Morozov, D. Jiang, Y. Zhang, S.V. Dubonos, I.V. Grigorieva, A.A. Firsov. Science, 306, 666 (2004).

[2] X. Du, I. Skachko, A. Barker, E.Y. Andrei. Nature Nanotechnol., 3, 491 (2008).

[3] R.A. Nistor, M.A. Kuroda, A.A. Maarouf, G.J. Martyna. Phys. Rev. B, 86, 041409 (2012).

[4] S. Goniszewski, M. Adabi, O. Shaforost, S.M. Hanham, L. Hao, N. Klein. Sci. Rep., 6, 22858 (2016).

[5] W. Xu, T.-W. Lee. Mater. Horiz., 3, 186 (2016).

[6] K. Brenner, Y. Yang, R. Murali. Carbon, 50, 637 (2012).

[7] V. Umansky, R. de-Picciotto, M. Heiblum. Appl. Phys. Lett., 71, 683 (1997).

[8] S. Ryu, L. Liu, S. Berciaud, Y.-J. Yu, H. Liu, P. Kim, G.W. Flynn, L.E. Brus. Nano Lett., 10, 4944 (2010).

[9] K. Nagashio, T. Yamashita, T. Nishimura, K. Kita, A. Toriumi. J. Appl. Phys., 110, 024513 (2011).

[10] D. Bishoff, T. Krähenmann, S. Dröscher, M.A. Gruner, C. Barraudm, T. Ihn, K. Ensslin. Appl. Phys. Lett., 101, 203103 (2012).

Редактор Л.В. Шаронова

\section{Edge doping in graphene devices on $\mathrm{SiO}_{2}$ substrates}

\author{
G.Yu. Vasilyeva ${ }^{1}$, D. Smirnov ${ }^{2}$, Yu.B. Vasilyev ${ }^{1}$, \\ A.A. Greshnov' ${ }^{1}$, R.J. Haug ${ }^{2}$ \\ ${ }^{1}$ loffe Institute, \\ 194121 St. Petersburg, Russia \\ 2 Institut fur Festkorperphysik, \\ Leibniz Universitat Hannover, \\ D-30167 Hannover, Germany
}

\begin{abstract}
The conductivity of $0.5-4 \mu \mathrm{m}$ wide monolayer and bilayer graphene ribbons produced by the technique of plasma etching in oxygen was experimentally studied. The dependence of the electron concentration in graphene on the tape width was observed. The effect is explained by the edge doping of graphene due to defects located in $\mathrm{SiO}_{2}$ near the edges of the ribbons. We propose a method for formation of sharp $p-n$-transitions in graphene and the structures with a constant gradient of electron concentration in the graphene plane, using edge doping.
\end{abstract}

